\title{
Thermo regulated clothing with phase change materials
}

\begin{abstract}
Clothing that responds to the environmental changes and adapts accordingly to make the wearer comfort this to be a long time challenge to the Textile engineers. Integrating various material sciences with that of textiles have yielded many tailor made intelligent textile structures. This paper is concerned about the application of phase change materials into the thermal comfort regulation of textile clothing. Materials that are capable of storing and dissipating heat energy at their unique conditions are identified and that could cope up with textile fibrous materials have been successfully implemented by a variety of techniques like micro encapsulation, coating etc. These integrated structures perform the action of either absorbing or releasing heat to keep the person in comfort. This paper elaborates their specified background of successful integration and implementation that serve its best to the customer concerned.
\end{abstract}

Volume 4 Issue 5 - 2018

\author{
V Ramesh Babu,A Arunraj \\ Department of Textile Technology, Kumaraguru College of \\ Technology, India
}

\begin{abstract}
Correspondence: Dr.V Ramesh Babu,Associate Professor Department of Textile Technology, Kumaraguru College of Technology, Chinnavedampatty, Coimbatore-641049, Tel 919944000055,Email salemramess@yahoo.com
\end{abstract}

Received: July 30, 2018 | Published: October 17, 2018

Keywords: intelligent textiles, phase change materials, micro encapsulation

\section{Introduction}

Our human body is a thermo-regulated organism. The body constantly generates heat, $\mathrm{CO}_{2}$ and $\mathrm{H}_{2} \mathrm{O}$ by the metabolism of food and muscle activity. The human body controls the release speed of heat by blood vessel dilatation temperature. It has been shown that the most comfortable skin temperature is $31.4^{\circ} \mathrm{C}$. When the temperature of any part of the skin differs by within $1.5-3.0^{\circ} \mathrm{C}$ of this ideal temperature, the human body is unaware of the warmth or coolness. If the difference is more than $\pm 4.5^{\circ} \mathrm{C}$, the human body feels discomfort. In addition, a core body temperature of $36.5^{\circ} \mathrm{C}$ is required, and a rise or fall of $1.5^{\circ} \mathrm{C}$ can be fatal. A balance between the rates of heat loss and generated must be maintained.

Textiles that are capable of being reactive to the stimuli rendered externally or internally to maintain the desired level of specified applications are called Smart or Intelligent textiles. These structures are of paramount importance because of their specificity and reactive nature. Smart textiles refer to those which could change color, display images, keep controlled micro atmosphere of humans and so on. These enhancements could be brought up either in their fibrous stage, designing stages or by special finishes.

\section{Textiles and comfort}

Conventional textile materials such as cotton, hemp, silk, wool and polyester, polyamide and acrylic fibers etc., provide a degree of resistance to body heat loss, which is determined by the number of air pockets present in the fabric. To keep the skin temperature within the desired level, we must put on or take off clothing according to the external temperature. This would become more difficult for a man to spend a lot of finance and time only for the purpose of making himself comfort, in the present information age. Hence there is a huge scope of market for a fabric that suits all climatic conditions. Instead of changing the clothing according to climatic conditions, if the clothing is designed such that it could automatically change to the external stimuli would gather tremendous momentum in clothing market where comfort became major factor. This could be achieved by placing thermal responsive phase change materials with textile ones so that the task is accomplished.

\section{Functions of phase change material (PCM) in clothing}

The major functions that a Phase change material (PCM) is ought to perform when incorporated with a textile substrate are

a. Cooling - by heat absorption

b. Heating - by heat release

c. Thermo regulating - resulting in combination of cooling and heating

\section{Phase change materials science}

\section{Phase transition}

In thermodynamics, phase transition or phase change is the transformation of a thermodynamic system from one phase to another. The distinguishing characteristic of a phase transition is abrupt changes in one or more physical properties, in particular the heat capacity, with a small change in a thermodynamic variable such as the temperature. In the English vernacular, the term is most commonly used to describe transitions between solid, liquid and gaseous states of matter, in rare cases including plasma (Figure 1). ${ }^{1}$

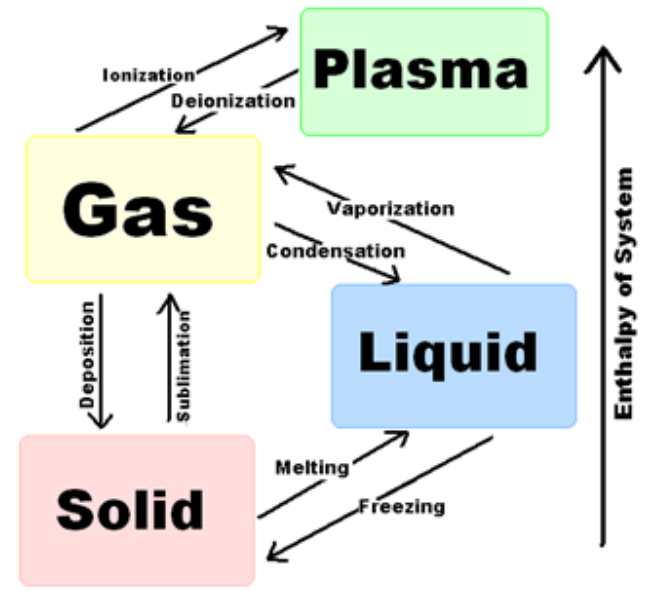

Figure I Transformation of a thermodynamic system from one phase to another. 


\section{Phase change materials}

Phase change materials are a kind of heat storage materials. These heat storage materials can be classified into sensible heat storage materials and latent heat storage materials. Sensible heat storage materials that undergo obvious temperature change during their phase change. ${ }^{1}$ Water, steel and stone are common examples. Latent heat storage materials that undergo phase change with slight temperature changes. They could be repeatedly converted from solid to liquid to gas and vice versa. These are technically termed as phase change materials. PCMs that could be used in textiles and clothing must lie in the temperature interval as specified, heat absorbing temperature interval is 20 to $40^{\circ} \mathrm{C}$ and heat releasing temperature interval is 30 to $10^{\circ} \mathrm{C}$. The phase change temperature of hydrated inorganic salts, polyhydric alcohol - water solution, polyethylene glycol (PEG), polytetramethylene glycol (PTMG), aliphatic polyester, linear chain hydrocarbon, hydrocarbon alcohol, hydrocarbon acid, etc., is in this interval.

Phase change materials that have been successfully applied for textiles are explained as follows (Table 1):

Hydrated inorganic salts: They are inorganic salt crystals with

Table I Phase change materials

\begin{tabular}{lllll}
\hline $\begin{array}{l}\text { Avg. molecular weight }(\mathrm{g} / \\
\mathbf{m o l})\end{array}$ & $\begin{array}{l}\text { Melting point } \\
\left({ }^{\circ} \mathbf{C}\right)\end{array}$ & $\begin{array}{l}\text { Melting heat } \\
\mathbf{J} / \mathbf{g}\end{array}$ & $\begin{array}{l}\text { Crystallization point } \\
\left({ }^{\circ} \mathbf{C}\right)\end{array}$ & $\begin{array}{l}\text { Crystallization heat } \\
{[\mathrm{J} / \mathrm{g}]}\end{array}$ \\
\hline 1000 & 35.1 & 137.31 & 12.74 & 134.64 \\
2000 & 53.19 & 178.82 & 25.19 & 161.34 \\
4000 & 59.67 & 189.69 & 21.97 & 166.45 \\
6000 & 64.75 & 188.98 & 32.89 & 160.93 \\
10000 & 66.28 & 191.9 & 34.89 & 167.87 \\
\hline
\end{tabular}

Table 2 Thermal properties hydrated inorganic salts materials

\begin{tabular}{|c|c|c|c|c|c|c|c|}
\hline \multirow[t]{2}{*}{ Salt } & \multirow{2}{*}{$\begin{array}{l}\text { Melting point } \\
\left({ }^{\circ} \mathrm{C}\right)\end{array}$} & \multirow{2}{*}{$\begin{array}{l}\text { Melting heat } \\
\mathrm{J} / \mathrm{g}\end{array}$} & \multicolumn{2}{|c|}{ Density $\mathrm{g} / \mathrm{m}^{3}$} & \multicolumn{2}{|c|}{$\begin{array}{l}\text { Specific heat capacity ( } \\
\left.\mathrm{J} / \mathrm{g}{ }^{\circ} \mathrm{C}\right)\end{array}$} & \multirow{2}{*}{$\begin{array}{l}\text { Heat storage } \\
\text { density J/g }\end{array}$} \\
\hline & & & Solid & Liquid & Solid & liquid & \\
\hline $\mathrm{CaCl}_{2} \cdot 6 \mathrm{H}_{2} 0$ & 29 & 190 & 1800 & 1560 & 1460 & 2130 & 283 \\
\hline $\mathrm{Na}_{2} \mathrm{SO}_{4} \cdot 10 \mathrm{H}_{2} \mathrm{O}$ & 32 & 225 & 1460 & 1330 & 1760 & 3300 & 300 \\
\hline $\mathrm{Na}_{2} \mathrm{SO}_{4} \cdot 5 \mathrm{H}_{2} \mathrm{O}$ & 43 & 209 & 1650 & - & 1460 & 2300 & 345 \\
\hline
\end{tabular}

\section{Phase change behavior of pet}

Linear chain hydrocarbons: Linear chain hydrocarbons are byproducts of oil refining which are non-toxic, inexpensive and extensive source of raw materials suitable for usage. They are the most impor- n-water molecules. These salts are lying in the desired interval of $20^{\circ} \mathrm{C}$ to $40^{\circ} \mathrm{C}$ to be applied for thermo-regulated clothing. Some of the useful hydrates are shown in the table with their thermal properties (Table 2)

Polyhydric alcohol: The following materials produce endothermic and exothermic effects without a change instate at temperatures far below the melting point of the substances:

\section{i. 2,2-dimethyl-1,3-propanediol(DMP)}

ii. 2 - hydroxymethyl - 2 - methyl - 1,3 - propanediol (HMP)

iii. 2 - bis - (hydroxyl methyl) - 1,3-propanediol

However, they are not suitable for manufacture of heat storage textiles due to their temperature range being higher than $40^{\circ} \mathrm{C}$. Attempts have been made to mix two or more such elements into compounds whose range may lie undesired level.

Polyethylene glycol: Polyethylene glycol is one of the important phase change material whose melting temperature is proportional to the molecular weight when less than 20000. And above this molecular weight the melting points are almost same. Some of PEGs whose MW lie behind 20000 are listed as follows.

Table 3 Phase change behavior of linear chain hydrocarbons

\begin{tabular}{lllll}
\hline Hydrocarbons & No. of carbon atoms & Melting point $\left({ }^{\circ} \mathbf{C}\right)$ & Melting heat $\mathbf{~} / \mathbf{g}$ & Crystallization point $\left({ }^{\circ} \mathbf{C}\right)$ \\
\hline $\mathrm{n}$ - hexadecane & 16 & 16.7 & 236.58 & 16.2 \\
$\mathrm{n}$ - heptadecane & 17 & 21.7 & 171.38 & 21.5 \\
$\mathrm{n}$ - octadecane & 18 & 28.2 & 242.44 & 25.4 \\
$\mathrm{n}$ - eicosane & 20 & 36.6 & 246.62 & 30.6 \\
$\mathrm{n}$ - heneicosane & 21 & 40.2 & 200.64 & - \\
\hline
\end{tabular}

tant of all the PCMs applied for heat storage and thermo regulated textiles. Their melting and crystallization points range from $10^{\circ} \mathrm{C}$ to $40^{\circ} \mathrm{C}$. Some of the commonly used hydrocarbons are listed in the Table 3 . 


\section{Micro-encapsulation of PCMs}

As discussed before, as phase change materials are migrating their states from solid to liquid and vice versa, they tends to flow due to increased segmental mobility of atoms. This may deteriorate the durability of PCM in specified application. For this purpose, the PCMs have to be encapsulated or bound by a thin layer of polymeric or any other material so that the phase transition could be accomplished inside a controlled environment for several repetitive cycles. There is variety of methods to encapsulate them onto a film in micro dimensions. The following table shows the dimension of microcapsules produced by various techniques (Table 4) (Table 5).

Table 4 Particle size of different micro encapsulation process

\begin{tabular}{ll}
\hline Micro encapsulation process & Particle size $(\mathbf{1 0 - 6 m})$ \\
\hline Spray - drying & $5-5000$ \\
Fluid bed coating & $20-1500$ \\
Coacervation & $2-1200$ \\
Interfacial polymerization & $0.5-1000$ \\
Sol - gel encapsulation & $2-20$ \\
Layer by layer assembly & $0.02-20$ \\
Solvent evaporation & $0.5-1000$ \\
Rotating disc & $5-1500$ \\
\hline
\end{tabular}

Table 5 Methods of Micro encapsulation

\begin{tabular}{lll}
\hline Chemical methods & Physical methods & $\begin{array}{l}\text { Physico mechanical } \\
\text { methods }\end{array}$ \\
\hline $\begin{array}{l}\text { Suspension, dispersion } \\
\text { and emulsion } \\
\text { polymerization }\end{array}$ & Coacervation & Spray drying \\
Polycondensation & $\begin{array}{l}\text { Layer by layer } \\
\text { assembly }\end{array}$ & $\begin{array}{l}\text { Multiple nozzle } \\
\text { spraying }\end{array}$ \\
& Sol-gel encapsulation & Fluid bed coating \\
& Supercritical methods & $\begin{array}{l}\text { Centrifugal } \\
\text { techniques }\end{array}$ \\
& & $\begin{array}{l}\text { Vacuum and } \\
\text { electrostatic } \\
\text { encapsulation }\end{array}$ \\
\hline
\end{tabular}

\section{Manufacturing techniques}

Filling or impregnating: In this method, the fibers that are hollow or porous in nature are kept immersed into a solution containing desired concentration of PCMs for specified time, under pressure. This makes the dispersed capsules to migrate from solvent media to fibrous structure and gets fixed into them.

Fiber spinning: Microcapsules of various shapes - round, square and triangular within fibers at the polymer stage. The PCM microcapsules are permanently fixed within the fiber structure during the wet spinning procedure of fiber manufacture. Micro encapsulation gives a softer hand, greater stretch, more breathability and air permeability to the fabrics. The pictures show the acrylic fibers spun with PCMs (Figure 2).

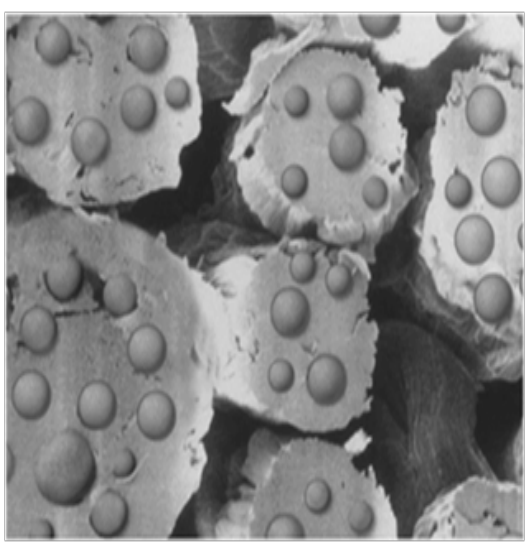

Figure 2 Acrylic fibers spun with PCMs.

Matrix coating during the finishing process: The PCM microcapsules are embedded in a coating compound like acrylic, polyurethane, etc, with certain binders and are applied to the fabric. There are many coating methods available like knife-over-roll, knife-over-air, pad-dry-cure, gravure, dip coating and transfer coating (Figure 3).

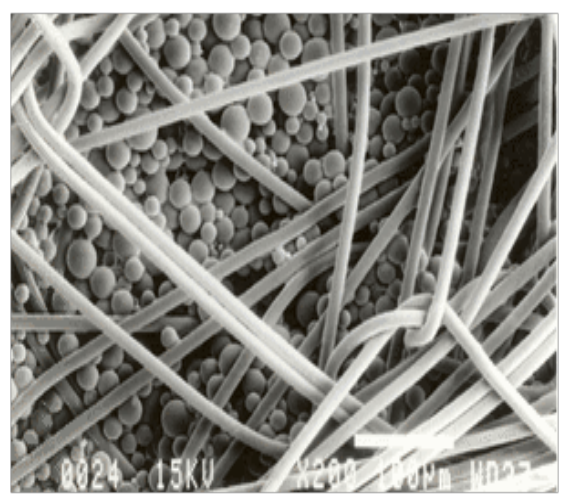

Figure 3 The PCM microcapsules using matrix coating.

Foam dispersion: Microcapsules are mixed into a water-blown polyurethane foam mix and these foams are applied to a fabric in a lamination procedure, where the water is removed from the system by the drying process.

\section{Properties of PCM incorporated textiles}

\section{Thermal resistance}

The thermal properties of PCM incorporated textiles have been studied with the apparatus designed by Pause, which was the only instrument available to assess directly. He made studies with different textile structures with different materials and concluded that the total thermal insulation of new (PCM) exceeds $60 \%$ than that of conventional garments. Differential scanning calorimetry is a useful method but it could not directly be translated to thermal resistance behavior. A sample analysis result of PCM coated fabrics is given below. ${ }^{1,2}$

The dynamical thermal properties of PCM textiles are not a constant. It is noticed to differ during the measuring stage itself and hence it is preferred to follow a Gaussian distribution as similar to that of DSC curves (Table 6).

Thermo regulating properties: There is no direct method to assess the thermo regulating properties. Researchers have made simulated 
skin and clothing model and several more methods to investigate in this perspective. It was inferred that the cold whether clothing trials showed a usual drop of $3^{\circ} \mathrm{C}$ in the skin temperature for conventional fabrics whereas in PCM engineered one, its is only about $0.8^{\circ} \mathrm{C}$.

Table 6 PCM coated fabrics

\begin{tabular}{lllll}
\hline Materials tested & $\begin{array}{l}\text { Acrylic with } \\
\text { PCM }\end{array}$ & $\begin{array}{l}\text { Acrylic without } \\
\text { PCM }\end{array}$ & $\begin{array}{l}\text { Substrate with } \\
\text { PCM }\end{array}$ & $\begin{array}{l}\text { Substrate without } \\
\text { PCM }\end{array}$ \\
\hline Wt./sq.m & 270 & 250 & 227 & 207 \\
Stand thickness $(\mathrm{mm})$ & 5.4 & 5.63 & 0.63 & 0.61 \\
Thermal conductivity(w/mK) & 0.0398 & 0.0342 & 0.1012 & 0.1782 \\
Thermal resistance(sq.m.K/w) & 0.1281 & 0.1491 & 0.0057 & 0.0029 \\
Specific thermal capacity(kJ/kg.K) & 3.022 & 2.391 & 2.468 & 1.84 \\
\hline
\end{tabular}

\section{Applications}

Casuals: Heat storage and thermo regulated textiles can be used as face fabrics, liner fabrics, batting etc. Thermal underwear, jackets, sports garments and skiwear are the latest products in markets based on phase change technology.

Professional clothing: Fire fighter uniforms, bullet proof vests, diver's coveralls, space suits, airman suits, field uniforms, sailor suits etc are specially tailored garments. Special gloves for extremely high or low temperatures are being used.

Home textiles: Interior decorations, curtains, bed clothes, blankets, mattresses, pillows, sleeping bags etc. are some of the potential applications of thermo regulated textiles. Outlast ${ }^{\circledR}$ are the major players in producing products based on these intelligent textiles.

Footwear: Shoe linings, socks, ski boots and golf shoes are made with these materials are right solutions for tremendous heat released during drastic changes in wearer's head, body, hands and feet.

Medical usage: PEG treated fabrics may be useful in medical and hygiene applications where both liquid transport and anti- properties are desirable. These smart textiles can keep the skin temperature within comfort range, so they can be used as bandage for burn and heat/cool therapy. ${ }^{3-8}$

\section{Conclusion}

The applications of phase change technology has been gathering momentum since 1980 s and researches are constantly strengthened with improvements in cutting edges of fabricating phase change materials and applying them in a well defined distribution in textile substrates with precise control engineering techniques. Textile
Applications can be widened with a scope of insisting technical textile utilization of current matter of interest. Rigid is the bright future for the industry concerning with making people comfort with all perspectives, no matter how small the target may be. Future studies on military clothing will be focused which has tremendous potential applications of PCM.

\section{Acknowledgements}

None.

\section{Conflict of interest}

Author declares there is no conflict of interest in publishing the article.

\section{References}

1. Ruchi kholiya, Alka Goel. Thermoregulation and Clothing. Asian Textile Journal. 2007.

2. Sunita dixit, Alka Goel. Micro encapsulation In Textile Processing. Asian Textile Journal. 2007.

3. Xiaoming Tao. Smart fibers. Fabrics and clothing. 1st ed. Cambridge: Wood head Publishing Limited; 2001:34-57.

4. Mattila HR. Intelligent textiles and clothing. Cambridge: Wood head Publishing Limited; 2006:19-82.

5. http://www.outlast.com

6. http://ezinearticles.com/?Pcm-In-Textiles\&id=367030

7. http://www.microteklabs.com/technical_overview.pdf

8. http://www.ispcorp.com/webseminar/seminar/presentations/personal/ seminar6/ 